\title{
A FEASIBILITY STUDY FOR IMPLEMENTATION OF A SMART PARKING SYSTEM IN PORT OF SPAIN TRINIDAD AND TOBAGO
}

\author{
Sarah Rooplal ${ }^{*}$, Boppana V. Chowdary ${ }^{2}$ \\ ${ }^{1,2}$ Faculty of Engineering, The University of the West Indies, Trinidad \\ ${ }^{1}$ Email: sroopla@gmail* (Corresponding author) \\ ${ }^{2}$ Email: boppana.chowdary@ sta.uwi.edu
}

\begin{abstract}
Parking challenges and problems are prominent worldwide as well as in Trinidad and Tobago. The capital city of Trinidad, Port Of Spain, is a major area where these challenges are experienced as there are approximately $30 \%$ of the population who venture into the city on a daily basis during the week. Worldwide trends involve the utilization of Internet of Things (IoT) platforms expected to alleviate parking challenges by implementation of contemporary parking models such as a smart parking system (SPS). This study investigated feasibility for implementation of a SPS in Port Of Spain.

In this study, a Discrete Event Simulation (DES) modelling approach was used to simulate real-life scenarios of the standard parking and a proposed SPS model for a facility chosen in Port Of Spain. These simulation models were executed effectively and results were validated. Verifications were done by comparing how the models worked, to the existing parking facility. Models were then validated using the Chi-squared statistic to determine if there were any statistical difference between developed models and actual statistic. The proposed SPS will reduce driver frustration in finding a vacant parking spot, fuel usage and also reduce environmental degradation.
\end{abstract}

Keywords: Smart Parking System; Discrete Event Simulation; Internet of Things. https://doi.org/10.47412/FZWN8308

\section{Introduction}

At present, almost all the large cities in the world are faced with traffic congestion which results in driver frustration, fuel wastage and environmental degradation [1]. Motorists entering Port Of Spain face the same challenges of traffic congestion as approximately $30 \%$ of the population enter the city per weekday [2] and there has been a rapid increase in the total number of vehicles registered which increased from 518,831 in the year 2010 to 1,016265 in the year 2017 [3]. One of the major causes of traffic congestion is parking problems. Interestingly the number of manufactured vehicles and vehicle owners increased rapidly, however the number of parks and traditional parking facilities remains unchanged [4]. Therefore, the process of finding vacant spots has grown into a common problem in most of urban cities throughout the world [1].

In this new era within the world of technology, there is a major aspect of modern life that is connected via the Internet of Things (IoT). Parking systems and various parking technologies are considered to be one of the "IoT" [5]. In Trinidad, IoT is an emerging market where machines are embedded with sensors which allows them to relay data with little or no human involvement [6]. Some examples of IoT in Trinidad are 
health fitness devices, home automation devices, Wi-Fi security surveillance cameras and voice-controlled products [7]. Telecommunications companies are currently looking at future development into IoT products and from the market research it is clear that there is a wider scope for smart phone penetration in Trinidad and Tobago [8].

Present day parking challenges in cities and towns can be solved with the help of smart parking technologies and systems [9]. Smart parking is described as being a system which assists drivers in finding a vacant space and obtain parking information by means of the smart phones or any other digital devices. Smart parking systems (SPS) and technologies use sensors, Bluetooth, wireless technologies and cloud computing services to locate vacant parking spots [10].

In this paper, a feasibility study is performed for implementation of a SPS in Port Of Spain by development of discrete event simulation (DES) models using Arena simulation programme. The DES approach allows to test real life parking scenarios without incurring high costs of prototyping [11].

\section{Trends in Smart Parking Systems}

Literature was reviewed over a time span of approximately 2 decades using various books, search engines such as Google Scholar and many online databases. These databases included IEEE Xplore Digital, ProQuest Dissertations and Theses Global, Springer Link and many more, also some Gartner Reports were accessed.

From the literature it was noted the parking problems experienced worldwide as well as in Trinidad and Tobago. The main observation is in terms of rapid increase in the number of private vehicles in urban areas. Furthermore, traditional parking facilities and roadways has remained unchanged over the years. These factors resulted in frustration of drivers, higher fuel usage, high maintenance costs of vehicles and environmental degradation [1]. Additionally, other parking problems consisted of non-availability of sufficient information on occupancy of parks, condition of existing parking facilities, parking spaces and pricing of parking facilities [12].

The Parking Network Report [13] explained the various types of parking systems seen worldwide as well as in Trinidad and Tobago. Kim et al. [14] mentioned that the parking systems are mainly managed by parking meters, ticket and card type devices. SPS however have a great advantage as it helps drivers in obtaining parking spot efficiently via various communication technologies [10]. Zajam and Dholay [15] categorized smart parking into parking type guidance and information system, park and ride system, Eparking system and automated systems. Further, with these smart parking technologies, traffic can be reduced. Thus, there is a need worldwide for cities to implement smart parking technologies and strategies. Worldwide these smart parking systems are all governed by IoT technologies which was explained in [16]. As per the Gartner's report [17], IoT is a sustainable technology and its inflated expectations will reach its highest activity of progress in the next 5 to 10 years.

In conclusion, to conduct this research, DES approach is selected as per the steps followed in [18]. Further, Arena Simulation Software will be used to run the simulations models [19]. In addition, as per the study of $\mathrm{Lu}$ et al. [20], the DES technique will be executed for verification and validation of the proposed SPS. Pham et al. [21] also explained the use of a cloud-based smart parking system to reduce driver's wait time. These pioneers' findings motivated the authors to implement the IoT based SPS in execution of the proposed DES models.

\section{Design of the Study}

This study incorporated the eight simulation steps followed by [18] for a successful simulation. The $1^{\text {st }}$ step of problem formulation was broken down into a research phase and research analysis. The research phase 
included market research that highlighted the number of vehicles registered in Trinidad and Tobago and its projected growth and product research of existing parking strategies. A car park in Edward Street, Port Of Spain, was selected for the study, this parking facility hosts 24 parking spots and is located in the surroundings of approximately 10 large organizations comprising of Government offices, private Enterprises and shopping plazas. The research analysis included generation and evaluation of customer needs and data collection. A questionnaire similar to [22] was distributed to commuters in Port Of Spain and shared via social media which gained the views of the public on smart parking approach and learned their use of parking facilities.

The $2^{\text {nd }}$ and $3^{\text {rd }}$ simulation steps, solution methodology, system and simulation specification were compiled into the concept development. This was done by generating a Quality Function Deployment (QFD) chart for smart parking technologies. The QFD chart is a combination of the customer needs, customer requirements which was obtained from the questionnaire distributed and the product and market research conducted. The customer requirements were rated of importance with 5 being the highest, 3 medium and 1 the lowest importance. The characteristics of a smart parking system was rated of importance with 9 being the highest, 3 being medium and 1 being the lowest importance. Importance percentage was then calculated for each customer requirement by means of Eq. (1). This was then used to calculate the importance and importance \% of each characteristic mapped to the customer needs by using Eq. (2). From this importance $\%$, the highest ranked characteristics were selected and used to develop the smart parking system concept.

$$
\text { Importance } \%=\left(\frac{\text { Customer requirements importance }}{\text { Total customer requirements importance ratings }}\right) \times(100)
$$

\section{Importance of Characteristic ratings of smart parking system $=($ Total (Customer Requirement Importance \% $\times$ Characteristic Rating))}

From the QFD chart the top-rated characteristics of smart parking are summarised below:

- $\quad$ Smartphone app $-15.7 \%$

- IoT connectivity $-13.5 \%$

- Cloud computing - $10.9 \%$

- RFID connectivity $-10.9 \%$

- Availability to check vehicle occupancy $-10.7 \%$

- RFID sensors $-9.2 \%$

These characteristics were then used to develop the concept for the proposed SPS and modelled using the Arena simulation program.

The $4^{\text {th }}$ simulation step of model formulation and construction was done by a concept generation and selection. The proposed SPS was generated based on the top-rated characteristics of the SPS from the QFD chart. These characteristics allowed for the integration with smartphone app into the system, IoT connectivity between devices, cloud computing, RFID connectivity and the availability to inquire before entering the parking facility with vehicle occupancy. All this information is highlighted in Fig. 1. The proposed SPS concept was designed similar to [21], however this concept has only connected to one parking facility as opposed to multiple parking facilities. It also incorporated an additional local server and an RFID antenna for continuous connectivity. 


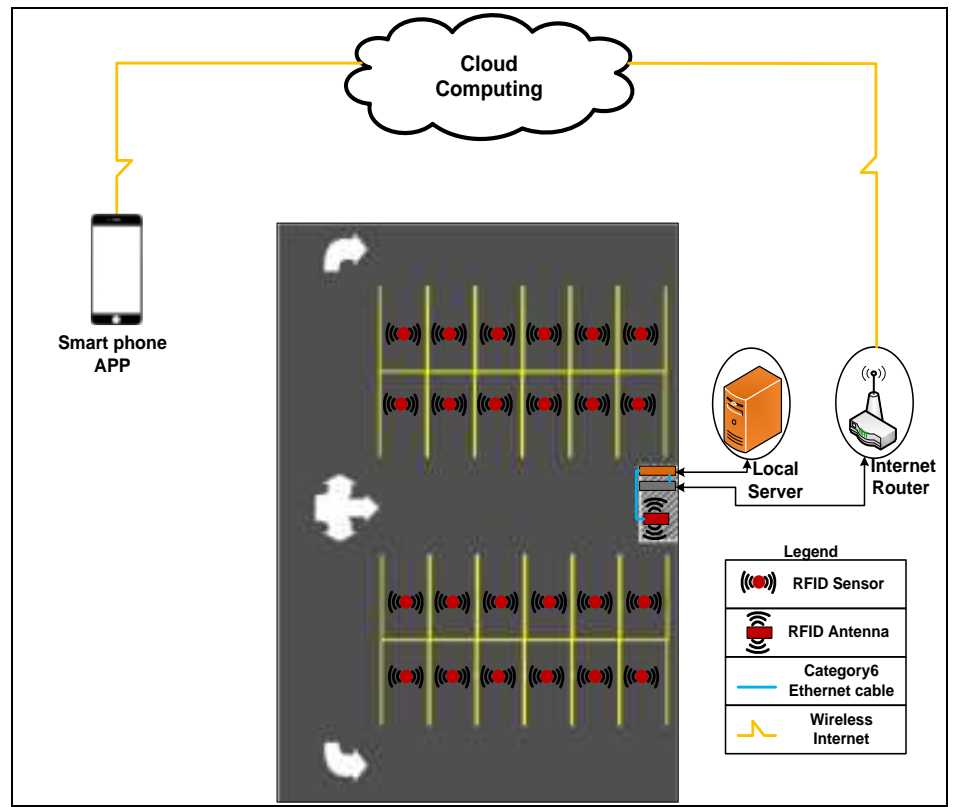

Figure 1: Generated Smart Parking System Concept

The generation of both conceptual models i.e. the standard and proposed smart parking model were built in Arena Simulation program using four modules; create, decide, process and dispose. They also contained sets which represented parking spaces or resources in the relevant lanes. The standard model was built with constant input variables to allow for validation of the model. The schedules and data collected from the fields were then inputted for validation purposes. The parameters were then changed in the standard model to create the proposed smart parking model and schedules and data collected were also inputted for validation purposes. In this study the independent variable is the method used to find a park. It can be achieved either through the standard or basic model or through the proposed SPS model. The dependent variable is the time taken to find a park in the parking facility. This variable was then measured and validated.

The $5^{\text {th }}, 6^{\text {th }}, 7^{\text {th }}$ and $8^{\text {th }}$ simulation steps of verification and validation of the model, experimentation and analysis on the model, presenting and preserving the simulation results and dissemination of the model were all included in the study for completeness of the simulation process. For verification purpose, the model being run for several replications and for longer periods of time, which allowed for the model output to be properly analysed and shared with subject matter experts for feedback. Validation was done on the existing model of parking strategies used, with the average times to find a park from the model simulation and the times to find a park with the data collection analysis. They were both validated using a student's ttest as shown in Eq. (3) to check if they were statistically different. Once there was no statistical difference, the experimental model was constructed and the time to find a park was analysed and compared with the existing parking information.

\section{Presentation and Analysis of Data}

\subsection{Data Collection}

As per Chrobok et al. [23], data was collected at the parking facility during a four-day period of Monday to Thursday within the hours of 6:00 a.m. to 6:00 p.m. All data were collected in minutes, an average of these data was then used for validation for the study. Arrival and departure rates, duration of stay, wait times and parking success rate were all collected and analysed. 


\subsection{Data Validation}

The variable of interest is the time to find a park, hence the wait time collected was used to fit the probability distribution in the proposed SPS model. This was done using a goodness of fit test in Arena's Software Input Analyzer, which is a built-in function used in probability distribution [24]. Kelton et al. [18] proposed the usage of the Input Analyzer to select the right fit distribution in modelling of DES models. The output data obtained from the Input Analyzer shows that a gamma distribution is the best fit for waiting times, this is displayed in a histogram as shown in Fig. 2. Rockwell [24] also states gamma distribution is commonly used for representation of time required for completion of tasks. Caicedo et al. [25] used a similar distribution for their parking reservation system.

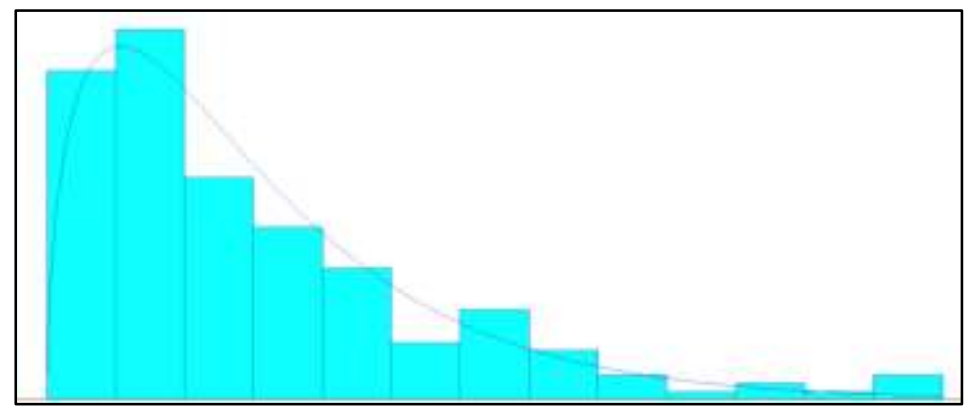

Figure 2: Histogram Distribution of Wait Times

From the Input Analyzer tool within the Arena Software, the distribution summary for the wait times is presented in Table 1.

Table 1: Distribution Summary of Wait Times from Arena's Input Analyzer

\begin{tabular}{|l|}
\hline Distribution Summary \\
Distribution: Gamma \\
Expression: GAMM $(4.66,1.53)$ \\
Mean Square Error: 0.004052 \\
\hline Chi Square Test \\
Number of intervals $=7$ \\
Degrees of freedom $=4$ \\
Test Statistic $=7.91$ \\
Corresponding p-value $=0.0962$ \\
\hline Data Summary \\
Number of Data Points $=183$ \\
Min Data Value $=0.3$ \\
Max Data Value $=30$ \\
Sample Mean $=7.13$ \\
Sample Std Dev $=6.14$ \\
Histogram Summary \\
Histogram Range $=0$ to 30 \\
Number of Intervals $=13$ \\
\hline
\end{tabular}

From the Input Analyser, the p-value can be observed as 0.0962. Anderson et al. [26] states that this p-value obtained from the Chi-squared test is used for hypothesis testing particularly for decision making whether to reject or not to reject the null hypothesis. Using a 95\% confidence limit [26] and a degree of freedom 
(DOF) of 4 , we can say p-value $=0.0962$ is greater than 0.05 . Hence the authors accepted the null hypothesis and can be proceeded to use the collected simulation data for further analysis.

\subsection{Simulation Models and Results}

\subsubsection{Standard Simulation Model}

The standard model built comprised of a create, a decide, four processes and a dispose modules. These modules made up the logic for a vehicle searching for a parking spot, parking for a duration of time and the exit of the parking facility. The flow and processes involved in this logic can be seen in Fig. 3. Simulations were run for 10 replications, obtaining an average wait time of 12.36 minutes.

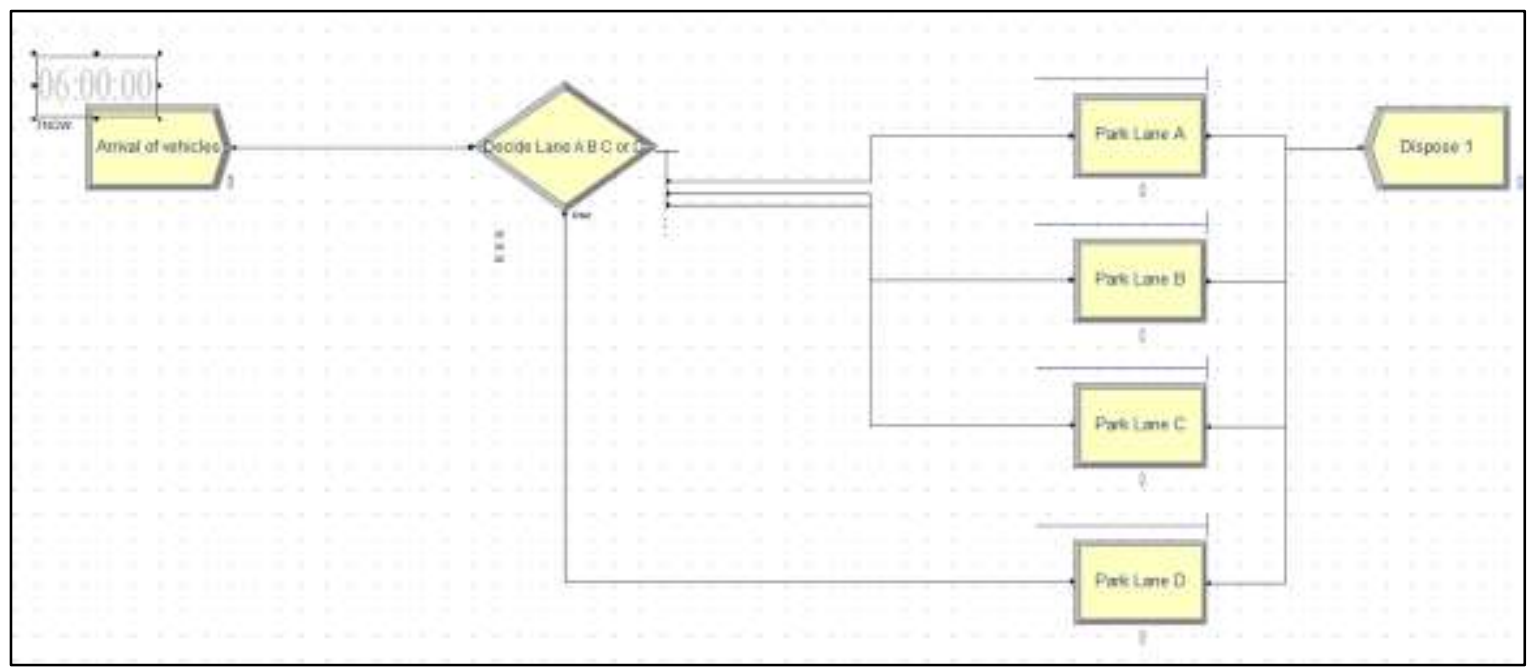

Figure 3: The Proposed Standard Parking Model Arrival, Parking Search and Departure Logic

\subsubsection{Proposed Smart Parking Simulation Model}

The proposed smart parking model utilizes the same model layout as the standard model. However, this model only allows vehicles to enter the parking facility once there is an available parking spot reserved by the driver in advance. The model's logic was designed differently in which the selection of a parking lane was done via an expression. The proposed model logic is depicted in Fig. 4. Simulations were run for the same 10 replications as in the standard model, obtaining an average wait time of 0 minutes. 


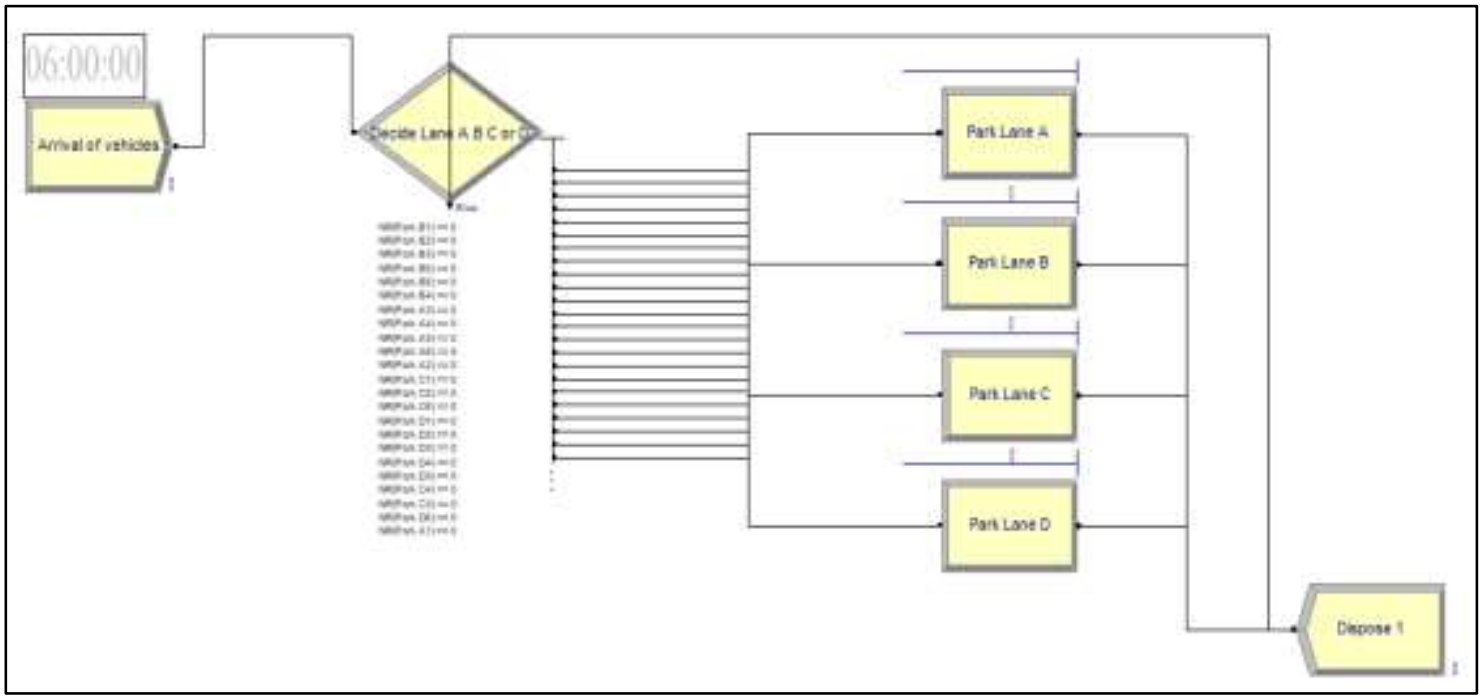

Figure 4: The Proposed Smart Parking Model Arrival, Parking Search and Departure Logic

\subsection{Current Parking Management}

Based on the questionnaire distributed it was observed that $79 \%$ of population experienced problems when locating a parking spot and $80 \%$ of persons are willing to pay for the utilisation of SPS where they can reserve their parking spot beforehand to eliminate the waiting time in locating a parking spot. Table 2 highlights the key findings from the questionnaire and its business impact.

Table 2: Test Data Analysis and Business Impact for the Standard and Proposed Smart Parking Models

\begin{tabular}{|l|l|}
\hline \multicolumn{1}{|c|}{ Test Data Analysis } & \multicolumn{1}{c|}{ Business Impact } \\
\hline $\begin{array}{l}\text { 80\% of the test data uses car parks in cities } \\
\text { and towns within Trinidad }\end{array}$ & $\begin{array}{l}\text { Positive impact for parking facilities as there is } \\
\text { a need for parking in cities and towns }\end{array}$ \\
\hline $\begin{array}{l}\text { The average time drivers would stay in } \\
\text { parking facilities are distributed over time, } \\
\text { some were less than an hour, 1-3 hours, 3-6 } \\
\text { hours and greater than 6 hours }\end{array}$ & $\begin{array}{l}\text { Positive impact for parking facilities since } \\
\text { there is a constant influx of vehicles. } \\
\text { Negative sometimes to drivers as they may not } \\
\text { know if the parking facilities are filled before } \\
\text { entry into the areas, this may result in some } \\
\text { wastage of time }\end{array}$ \\
\hline $\begin{array}{l}\text { 40\% of the test data took 10 -15 minutes to } \\
\text { locate a park within Port of Spain }\end{array}$ & $\begin{array}{l}\text { Negative impact for drivers and to the } \\
\text { environment as it adds to driver frustration and } \\
\text { it degrades the environment with GHG } \\
\text { emissions. } \\
\text { Positive for proposed SPS as this time can be } \\
\text { drastically reduced }\end{array}$ \\
\hline $\begin{array}{l}80 \% \text { of the test data supported the proposed } \\
\text { idea of the SPS }\end{array}$ & Positive impact for drivers and SPS \\
\hline
\end{tabular}

\section{Validation and Discussion}

The proposed smart parking model was developed after the standard model was validated. This was done by performing a student's t-test as per the Eq. (3) [27]. A decision was made at $95 \%$ confidence interval using 6 degrees of freedom and a two-tailed t-test. 


$$
t-v a l u e=\frac{\left|\mu_{1}-\mu_{2}\right|}{\sqrt{\frac{s_{1}^{2}}{n_{1}}+\frac{s_{2}^{2}}{n_{2}}}}
$$

In the study, the calculated t-value was found as 0.642 which is lower than the critical t-value of 2.447 , hence the null hypothesis was not rejected and it was proven that there was no statistical difference between the time to obtain a park in the real world at Edward Street and the time to obtain a park in the standard simulation model. Hence simulations were run and wait times in obtaining a parking spot were all listed in Table 3, which highlighted that there is no waiting time in the smart parking model.

Table 3: Comparison of Wait Times in the Standard and Smart Parking Models

\begin{tabular}{|l|c|c|c|}
\hline & Existing Parking Facility & Standard Model & Smart Parking Model \\
\hline Wait time & 7.84 minutes & 9.94 minutes & 0 minutes \\
\hline
\end{tabular}

For implementation of the proposed SPS, the return on investment was determined as $48 \%$ with a payback period of 24 months and an NPV of $\$ 41,639$. From the cost benefit analysis, it can be concluded that the proposed SPS reduces the waiting time to find a park as well as after two years it will be bringing profits to the owner. There will also be an economic impact by having savings associated with a reduced fossil fuel usage and less vehicle emissions.

\section{Conclusion and Recommendations}

The proposed smart parking system for the selected parking lot at Edward Street is an ideal facility to highlight the benefits of implementing SPS in the city of Port Of Spain. DES technique was used to simulate the real-life scenarios. From the proposed approach, the time to find a parking lot is the key variable of interest. Further, in the proposed SPS study, the waiting time was reduced drastically when compared to the standard model. Furthermore, the proposed SPS resulted in reduction in labour costs, guaranteed parking spots and traffic reduction within the parking facility surroundings.

The target market for implementation of the proposed SPS is the current private and Government parking facilities within Port Of Spain. These includes parking lots, malls, private enterprises, city councils and corporations. The proposed SPS utilizes IoT functions and wireless sensor networks. Mitigation against cyber-attacks in using the SPS could be in the form of encryptions using firewalls. Also, to ensure no jamming of the wireless networks, agreements are to be made with the Internet Service Provider (ISP) to have encryption of triple DES enabled in the internet router. For integrity purposes injection attacks are to be prevented by ensuring validation of the data by means of some web application.

With the implementation of the SPS, the parking facility would not require a parking attendant to be there during the hours of operation, however the parking facility's owner can remotely manage the operations or have someone do it through IoT functions. The car park can also be utilized efficiently and encourage more parking facilities to follow a similar trend. Future work can include investigation of additional ways for non-smartphone users to reserve parking spots at the entrance. In addition, the feasibility study can be expanded for multi-storey parking facilities and on-street parking. 


\section{References}

[1] Kumar, R. Arun, Adarash. Dhange, Chandan. Motekar, Ashwini. Hondadkatti, and Vaishnavi. Deshpande. 2018. "A Review on Smart Car Parking Technologies." International Journal of Innovations \& Advancement in Computer Science Volume 7 (Issue 3).

[2] Dr. Furlonge, Rae. 2008. Trinidad and Tobago Business Guide Transport, . Trinidad and Tobago.

[3] Central Statistical Office. 2018. "Latest Indicators ", accessed 22nd March, 2018. http://cso.gov.tt/latestindicators/.

[4] Joshi, Pranav. Riaz Khan. M, and Motiwalla. Luvai. 2011. "Global Review of Parking Management Systems and Strategies ", Operations and Infromation Systems, University of Massachusetts.

[5] Juliadotter, Nina V. 2016. "Hacking Smart Parking Meters " 2016 International Conference on Internet of Things and Applications (IOTA):191-196. doi: 10.1109/IOTA.2016.7562720.

[6] Islam, S.M Riazul, Kwak. Daehan, Kabir. MD. Humaun, Hossain. Mahmud, and Kwak. Kyung-Sup. 2015. "The Internet of Things for Health Care: A Comprehensive Survey." IEEE Access Volume 3. doi: 10.1109/ACCESS.2015.2437951.

[7] Fiberserv Caribbean Ltd. 2018. "Smart Home Solutions ", accessed 16th October, 2018. https://fiberservcl.com/who-we-are/.

[8] Telecommunications Authority of Trinidad and Tobago. 2017. "Annual Report ".

[9] Tratz-Ryan, Bettina. 2017. "Hype Cycle for Smart City Technologies and Solutions, 2017." (ID: G00314338):1-55.

[10] Hassoune, Khaoula, Dachry, Wafaa. Moutaouakkil, Fouad., Medromi, Hicham. . 2016. "Smart Parking Systems: A survey " IEEE 978-1-5090-5781-8/16/.

[11] Arena Simulation Software. 2018b. "What Arena Does." Rockwell Automation, accessed 1st December, 2017. https://www.arenasimulation.com.

[12] Lizbetin, Jan. and Ladislav. Bartuska. 2017. "The Influence of Human Factor on Congestion Formation on Urban Roads." 10th International Scientific Conference Transbaltica 2017: Transportation Science and Technology

[13] Parking Network. 2018. "Parking Facilities ", accessed June 2nd, 2018.http://www.parkingnet.com/about-parking/parking-facilities.

[14] Kim. Fernandez, Rachel. Yoka, and CAPP., eds. 2018. A guide to Parking Edited by International Parking Institute. 1 vols. New York: Routledge.

[15] Zajam, Ajay. and Surekha. Dholay. 2018. "Detecting Efficient Parking Space Using Smart Parking." IEEE 9th ICCCNT 2018.

[16] Srinivasan, Ramraj. and Arumugam. Jawahar. 2016. "Internet of things: issues in using mobile communication network." 3rd International Conference on Electrical, Electronics, Engineering Trends, Communication, Optimization and Sciences (EEECOS 2016), Tadepalligudem, India, 1-2 June 2016.

[17] Gupta, Anshul. and McIntyre, Angela. 2017. Hype Cycle for Sustainability Technology, 2017. edited by Gartner Inc.: Gartner Inc.

[18] Kelton, W.David, P.Sadowski. Randall, and A.Sadowski. Deborah. 2014. Simulation with Arena Edited by Mc Graw Hill. 5th ed: Mc Graw Hill.

[19] Arena Simulation Software. 2018a. "Model Verification and Validation ". Rockwell Automation accessed 22nd May, 2018. https://www.arenasimulation.com/blog/post/model-verification-and-validation. [20] Lu, Rongxing. Lin. Xiaodong, Zhu. Haojin, and Shen. Xuemin. 2009. "SPARK: A New VANETbased Smart Parking Scheme for Large Parking Lots " IEEE Communications Society subject matter experts for publication in the IEEE INFOCOM 2009 proceedings., Ontario Canada

[21] Pham, Thanh, Nam. Binh Nguyen, Duc. Chyi-Ren. Dow, and Der-Jiunn. Deng. 2015. "A Cloud-Based Smart-Parking System Based on Internet-of-Things Technologies." IEEE Access: The Journal for rapid open access publishing 3:1581-1591.

[22] Aalsalem, Mohammed Y. and Zada Khan. Wazir. 2016. "CampusSense - A Smart Vehicle Parking Monitoring and Management System using ANPR Cameras and Android Phones." ICACT Transactions on Advanced Communications Technology (TACT) 5 (2):809-815. 
[23] Chrobok, Roland. Kaumann. Oliver, Wahle. Joachim, and Schreckenberg. Michael. 2000. "Three Categories of Traffic Data: Historical, Current and Predictive." IFAC Control in Transportation Systems,:221-226.

[24] Rockwell, Automation. 2017. Arena Rockwell Automation User's Guide United States of America Rockwell Automation Company

[25] Caicedo, Felix. Blazquez. Carola, and Miranda. Pablo. 2012. "Prediction of parking space availability in real time." Elsevier:7281-7290. doi: 10.1016/j.eswa.2012.01.091.

[26] Anderson, David R. J. Sweeney. Dennis, A. Williams. Thomas, D. Camm. Jeffrey, and J. Cochran. James. 2017. Edited by Cincinnati: Cengage Learning. Vol. 8, Essentials of Statistics for Business and Economics.

[27] Montgomery, Douglas. and C Runger. George. 2014. Applied Statistics and Probability for Engineers Vol. 6. United States of America: John Wiley and Sons. 